\title{
Evaluation of the Polymerization Depth of Bulk Fill Resin Composites Polymerized by Different Procedures: An In-Vitro Study
}

\author{
Esra Ozyurt $^{1} \odot$, Aysegul Kurt ${ }^{2} \odot$, Handan Yildirim ${ }^{1} \odot$ \\ ${ }^{1}$ Trakya University, Faculty of Dentistry, Department of Restorative Dentistry \\ ${ }^{2}$ Trakya University, Faculty of Dentistry, Department of Prosthodontics \\ Correspondence Author: Esra Ozyurt \\ E-mail: esraozyurt@trakya.edu.tr \\ Received: $19.02 .2019 \quad$ Accepted: 07.09 .2019
}

\begin{abstract}
Objective: The aim of this study is to investigate the depth of cure (DOC) of the bulk fill composite samples prepared in different thicknesses with two different modes of light curing device with Vickers hardness tester.

Methods: Five different bulk-fill composite materials were used in the present study. 20 sample of $2 \mathrm{~mm}$ and 20 sample of $4 \mathrm{~mm}$ thick samples were prepared, 10 samples from each group were polymerized for 20 seconds with the standard mode (Mode 1) of the light curing device and 10 samples polymerized with soft-start mode (Mode 2) for 25 seconds ( $n=10$ ). Hardness measurements were made from the upper and lower surfaces of each sample and the hardness ratio was calculated. The statistical analysis was performed using three-way analysis of variance (ANOVA) and Tukey multiple comparisons $(p=0.05)$.

Results: The hardness ratios of all composites were determined to be over $80 \%$, which is clinically acceptable. There was a statistically significant difference between the DOC levels according to the composites $(p<0.05)$. There was a statistically significant difference according to the thickness $(p<0.05)$. There was no statistically significant difference according to polymerization procedures $(p>0.05)$.

Conclusions: The surface hardness ratios of all groups were determined to be over $80 \%$, which is clinically acceptable. The polymerization with soft start technique may not different from the standard-mode for polymerization depth.

Keywords: Composite resins, hardness, polymerization, LED
\end{abstract}

\section{INTRODUCTION}

One of the significant problems associated with lightpolymerized resin composites is the inability to maintain cure depth and the possibility of insufficient monomer conversion (1). Resin composites polymerize only at a certain depth depending on the light penetration into the material (2). It has been shown that insufficient polymerization can lead to a decrease in physical, mechanical properties of resin composites, fragmentation of the resin composite and negative biological reactions due to residual monomer toxicity (3-5).

In order to have sufficient polymerization, sufficient light from the light curing device, the appropriate wavelength range of light, and the exposure time of the material to the light are essential (6). Other factors such as type, color, and translucency of the resin composite, the thickness of the layer, the distance to the end of the light curing unit, the post-irradiation period, the size and distribution of the filler particles affect the depth of the polymerization as well (7-9).

The composite is applied in $2 \mathrm{~mm}$ layers to achieve polymerization in large cavities and to reduce polymerization shrinkage (5). The layering technique has some disadvantages including the possibility of space or contamination between the composite layers, errors in inter-layer bonding, the difficulty of placement due to limited access in small cavities, and prolongation of treatment time (10). "Bulk fill" resin composites have been developed in order to overcome these disadvantages. Bulk fill resin composites can be applied in a single layer up to $4-6 \mathrm{~mm}$.

The optical properties of resin composites can affect the light transmittance, therefore the mechanical properties and monomer conversion (11). Increasing the translucency of the material is an approach to improve the polymerization depth in bulk fill composites (12). To optimize the properties of the composite, bulk fill composites include new filler technologies, shrinkage stress relievers, polymer isolator modulators and light reactive photo initiator systems (1113). Bulk fill composites have a higher polymerization depth and less polymerization shrinkage than conventional resin composites (14).

Various techniques are used to determine the depth of polymerization. Moreover, polymerization could be examined by direct (Fourier Transform Infrared Spectroscopy-FTIR-, Raman Spectroscopy) and indirect (scraping, micro hardness) methods $(15,16)$. Different devices can be used to measure 
hardness. Due to the ease of application and measurement accuracy in dentistry, Vickers hardness tester is frequently used to measure the hardness of materials (17). Bouschlicher et al (18) have reported that the polymerization depth of the composite can be calculated by hardness method. In this method, hardness is measured from bottom and top surfaces of composite blocks of different thicknesses. The value obtained by dividing the base hardness value of the composites by the top hardness value is called the hardness ratio. It has been reported in the literature that the composite resin has an acceptable minimum hardness ratio of 0.80 to be sufficiently polymerized $(19,20)$.

The aim of this study is to examine the polymerization depth of the bulk-fill composite samples prepared in different thicknesses with Vickers hardness measurement following the polymerization with two different modes of the light emitting diode (LED) light curing device. Null hypotheses of the study are as follows; 1) There is no difference between the polymerization depths of bulk fill composites of different thicknesses. 2) There is no difference in polymerization depths of bulk fill composites polymerized with standard and soft start mode.

\section{METHODS}

Five different nanohybrid bulk fill composite material Ecosite (DMG, Germany), Filtek Posterior Bulk-Fill (3M, UK), Tetric N-Ceram Bulk Fill (Ivoclar Vivadent), Admira X-tra (Voco), Grandioso X-tra (Voco) - were used (Table 1). Universal color was used for each composite $A 2$ or for the composites which were not produced in A2 in order to standardize the effect of color difference on polymerization depth. The samples were prepared by placing the composite material in cylindrical Teflon molds of $5 \mathrm{~mm}$ diameter in 2 $\mathrm{mm}$ and $4 \mathrm{~mm}$ thickness. 20 pieces of $2 \mathrm{~mm}$ and 20 pieces of $4 \mathrm{~mm}$ thick samples were prepared for each composite by means of Teflon molds. Composite materials placed on the molds were compressed between two microscope plates with a transparent matrix band on the top surface to obtain a smooth surface. The power of the light curing device (Radii Plus, SDI) was controlled by a radiometer and all samples were polymerized with a light power of $1500 \mathrm{~mW} / \mathrm{cm}^{2}$. SDI Radii Plus light curing device that we used in our study is the second-generation LED with a wavelength range of 440$480 \mathrm{~nm}$. 10 samples from each group were polymerized for $20 \mathrm{sec}$. with the standard mode (Mode 1) of the LED light curing whereas 10 samples were polymerized for $25 \mathrm{sec}$. with the soft-start mode (Mode 2) of the LED light curing device $(n=10)$. Soft start mode revealed a reduced intensity for the first 5 seconds before irradiation at 100\% intensity. The samples were light cured via a transparent matrix band to prevent oxygen inhibition zone formation. The samples were kept in distilled water at $37{ }^{\circ} \mathrm{C}$ for 24 hours in a dark environment to complete the polymerization. Subsequently, $300 \mathrm{gr}$ load from the upper and lower surface of each sample were subjected to 3 Vickers hardness measurements (Tronic, Digital Microhardness Tester DHV-1000) for 15 seconds. The upper and lower surface hardness ratios of each sample were calculated and recorded. The statistical analysis of the findings of the study was performed using the one-way analysis of variance (ANOVA) and Tukey multiple comparisons $(p=0.05)$.

Table 1. The materials and product details used in the study.

\begin{tabular}{|c|c|c|c|c|c|c|}
\hline RBC, color & Manifacturer & Matrix & Filler & Filler content & Photo initiator & $\begin{array}{c}\text { Filler size } \\
(\mu \mathrm{m})\end{array}$ \\
\hline $\begin{array}{l}\text { Filtek Bulk Fill } \\
\text { Posterior, A2 }\end{array}$ & 3M Espe, USA & $\begin{array}{l}\text { AUDMA, } \\
\text { AFM,DDMA, UMA }\end{array}$ & $\begin{array}{l}\text { Ytterbium trifluoride } \\
\text { (YbF3), zirconia filler, } \\
\text { silica filler }\end{array}$ & $76 / 58$ & Camphorquinone & $0,004-0,01$ \\
\hline GrandioSO, A2 & Voco, Germany & $\begin{array}{l}\text { Bis-GMA, Bis-EMA, } \\
\text { TEGDMA }\end{array}$ & $\begin{array}{l}\text { Glass ceramic fillers, } \\
\text { functionalised } \mathrm{SiO} 2\end{array}$ & $89 / 73$ & Camphorquinone & - \\
\hline $\begin{array}{l}\text { Tetric N-Ceram Bulk } \\
\text { Fill, A }\end{array}$ & $\begin{array}{l}\text { Ivoclar Vivadent, } \\
\text { Liechtenstein }\end{array}$ & Bis-GMA - UDMA & $\begin{array}{l}\text { Barium alumino silicate } \\
\text { glass, prepolymer filler }\end{array}$ & $75 / 53$ & $\begin{array}{l}\text { Lucirin, Ivocerin, } \\
\text { camphorquinone }\end{array}$ & $0,4-0,7$ \\
\hline $\begin{array}{l}\text { Admira Fusion X-tra, } \\
\text { Universal }\end{array}$ & Voco, Germany & $\begin{array}{l}\text { Organically } \\
\text { modified silicic acid }\end{array}$ & $\begin{array}{l}\text { Ba-Al-Si-glass/Silica } \\
\text { nanoparticles }\end{array}$ & $84 / 70$ & Camphorquinone & $0.05-10$ \\
\hline Ecosite, Universal & DMG, Germany & Bis-GMA & Barium glass & $82 / 65$ & Camphorquinone & $0,02-0.07$ \\
\hline
\end{tabular}

\section{RESULTS}

The following results were obtained when the effect of composite, thickness and polymerization procedure on DOC (Table 2) were considered; No statistically significant difference was found between DOC levels according to composites $(p<0.05)$. There was a statistically significant difference between the DOC levels according to the thickness $(p<0.05)$ whereas was no statistically significant difference between DOC levels according to polymerization procedures $(p>0.05)$.

When the $2 \mathrm{~mm}$ thickness Mode 1 was used, the mean DOC of the Tetric composite was found significantly lower than all other composites $\left(p_{1}: 0.019 ; p_{2}: 0.004 ; p_{3}: 0.001 ; p_{4}: 0.049\right.$; $\mathrm{p}<0.05)$. There were no statistically significant differences between Ecosite, Filtek, Grandioso and Admira X-tra composites ( $p>0.05$ ) (Table 3 ). 
Table 2. Evaluation of the effect of composite, thickness and polymerization procedure on DOC. Three way ANOVA Test, * $p<0.05 ; \mathrm{df}$ : degree of freedom; F: the F-statistic

\begin{tabular}{|l|c|c|c|c|c|}
\hline \multicolumn{1}{|c|}{ Source } & $\begin{array}{c}\text { Type III } \\
\text { Sum of } \\
\text { Squares }\end{array}$ & df & Mean Square & F & p \\
\hline Composite & 0,168 & 4 & 0,042 & 13,031 & $0,000^{*}$ \\
\hline Tickness & 0,039 & 1 & 0,039 & 12,077 & $0,001^{*}$ \\
\hline $\begin{array}{l}\text { Polymerization } \\
\text { procedure }\end{array}$ & 0,002 & 1 & 0,002 & 0,542 & 0,463 \\
\hline
\end{tabular}

When the $2 \mathrm{~mm}$ thickness Mode 2 was used, the average DOC of the Tetric composite was found to be significantly lower than the Ecosite, Filtek and Grandioso composites $\left(p_{1}: 0.012 ; p_{2}: 0.001 ; p_{3}: 0.031\right)$. The DOC average of Admira $X$-tra composite was significantly lower than the Filtek composite $\left(p_{1}: 0.016\right)$ (Table 3 ).

When the $4 \mathrm{~mm}$ thickness Mode 1 was used, the DOC average of Grandioso composite was significantly higher than Ecosite and Tetric composites $\left(p_{1}: 0.020 ; p_{2}: 0.028\right)$ (Table 3 ).

When the $4 \mathrm{~mm}$ thickness Mode 2 was used, the DOC average of the Filtek composite was significantly higher than the Tetric composite $\left(p_{1}: 0.026\right)$ (Table 3$)$.

Table 3. Intergroup comparisons of DOC according to thickness and polymerization procedures. One way ANOVA Test; * $p<0.05$

\begin{tabular}{|l|l|l|l|c|}
\hline Tickness & $\begin{array}{l}\text { Polymerization } \\
\text { procedures }\end{array}$ & Material & DOC & p \\
\hline $\mathbf{2 ~ m m}$ & Mode 1 & Ecosite & $0,91 \pm 0,05$ & $0,001^{*}$ \\
\hline & & Tetric & $0,83 \pm 0,05$ & \\
\hline & & Filtek & $0,93 \pm 0,09$ & \\
\hline & & Grandioso & $0,94 \pm 0,02$ & \\
\hline & & Admira X-tra & $0,9 \pm 0,05$ & \\
\hline & Mode 2 & Ecosite & $0,92 \pm 0,04$ & $0,000^{*}$ \\
\hline & & Tetric & $0,82 \pm 0,07$ & \\
\hline & & Filtek & $0,95 \pm 0,03$ & \\
\hline & & Grandioso & $0,9 \pm 0,03$ & \\
\hline & & Admira X-tra & $0,87 \pm 0,07$ & \\
\hline & Mode 1 & Ecosite & $0,83 \pm 0,08$ & $0,018^{*}$ \\
\hline & & Tetric & $0,83 \pm 0,06$ & \\
\hline & & Filtek & $0,87 \pm 0,07$ & \\
\hline & & Grandioso & $0,91 \pm 0,04$ & \\
\hline & & Admira X-tra & $0,85 \pm 0,04$ & \\
\hline & Mode 2 & Ecosite & $0,9 \pm 0,04$ & $0,010^{*}$ \\
\hline & & Tetric & $0,83 \pm 0,09$ & \\
\hline & & Filtek & $0,92 \pm 0,04$ & \\
\hline & & Grandioso & $0,85 \pm 0,07$ & \\
\hline & & Admira X-tra & $0,90 \pm 0,05$ & \\
\hline & & & & \\
\hline & & & & \\
\hline & & & & \\
\hline & & & & \\
\hline & & &
\end{tabular}

Intragroup comparisons of DOC according to thickness and polymerization procedures were shown in Table 4.
Table 4. Intragroup comparisons of DOC according to thickness and polymerization procedures. Student $t$ test; ${ }^{*} p<0.05$.

\begin{tabular}{|l|c|c|c|c|}
\hline & & DOC & & \\
\hline & & Mode 1 & Mode 2 & \\
\hline Material & Tickness & Mean \pm SD & Mean \pm SD & p \\
\hline Ecosite & $2 \mathrm{~mm}$ & $0,91 \pm 0,05$ & $0,92 \pm 0,04$ & 0,732 \\
\hline & $4 \mathrm{~mm}$ & $0,83 \pm 0,08$ & $0,90 \pm 0,04$ & $0,028^{*}$ \\
\hline Tetric & $\mathrm{p}$ & $0,014^{*}$ & 0,268 & \\
\hline & $2 \mathrm{~mm}$ & $0,83 \pm 0,05$ & $0,82 \pm 0,07$ & 0,685 \\
\hline & $4 \mathrm{~mm}$ & $0,83 \pm 0,06$ & $0,83 \pm 0,09$ & 0,944 \\
\hline & $\mathrm{p}$ & 0,929 & 0,769 & \\
\hline & $2 \mathrm{~mm}$ & $0,93 \pm 0,09$ & $0,95 \pm 0,03$ & 0,416 \\
\hline & $4 \mathrm{~mm}$ & $0,87 \pm 0,07$ & $0,92 \pm 0,04$ & 0,062 \\
\hline & $\mathrm{p}$ & 0,113 & $0,045^{*}$ & \\
\hline Grandioso & $2 \mathrm{~mm}$ & $0,94 \pm 0,02$ & $0,90 \pm 0,03$ & $0,011^{*}$ \\
\hline & $4 \mathrm{~mm}$ & $0,91 \pm 0,04$ & $0,85 \pm 0,07$ & $0,017^{*}$ \\
\hline & $\mathrm{p}$ & 0,123 & $0,036^{*}$ & \\
\hline Admira X-tra & $2 \mathrm{~mm}$ & $0,9 \pm 0,05$ & $0,87 \pm 0,07$ & 0,348 \\
\hline & $4 \mathrm{~mm}$ & $0,85 \pm 0,04$ & $0,90 \pm 0,05$ & $0,023^{*}$ \\
\hline & $\mathrm{p}$ & $0,024^{*}$ & 0,318 & \\
\hline
\end{tabular}

\section{DISCUSSION}

Optical microscopy and scraping methods could reveal the results of curing depth higher than the actual value when compared to hardness and conversion degree determination methods (21). However, FTIR has been reported to be less sensitive than hardness assessment to identify small changes in the degree of conversion (22). The degree of conversion of resin composites can be examined indirectly by Vickers or Knoop surface hardness measurements (23). In our study, Vickers hardness measurement was used to determine the depth of polymerization.

Studies in the literature have reported that the shape, rate, and type of filler particles significantly affect the light transmittance and the polymerization of the material (24). The filler sizes and ratios of the composites used in the study were different from each other. This could have caused the differences in polymerization depth. In our opinion, the filler ratio of Tetric $\mathrm{N}$-Ceram Bulk fill composite being lower than the other composites together with the larger filler particle size may have a negative effect on the light transmittance. In the studies of Tarle (25), it has been noted that the light transmittance of Tetric Evo Ceram, being less than other bulk fill composites in the filler ratio studies was found to be lower by examining the polymerization of bulk fill composites.

Due to the differences in refractive indexes between the inorganic filler and resin matrix, they have stated that light scattering increases in the materials with large fill-matrix interface area and reduces light transmittance (25). 
Bis-EMA and low-viscosity urethane-derived monomers have been reported to show generally a higher degree of conversion than typical Bis-GMA/TEGDMA resins (25-27). In our study, the samples of Bis-EMA-containing Grandioso bulk fill composite polymerized in standard mode in $4 \mathrm{~mm}$ thickness showed a higher cure depth than the Bis-GMA containing Ecosite and Tetric groups. Bis-EMA could have been effective for the difference.

Although camphorquinone is currently used in all resinbased composites, some bulk fill composites also contain alternative photoinitiators activated at lower wavelengths of light. These composite resins benefit from the use of a broad-spectrum light source giving blue as well as purple light (28). As the lower wavelengths of light (in the purple range) did not penetrate deep into the composite resin, it has been reported that the polymerization may be reduced due to insufficient activation of alternative photoinitiators in deeper regions $(29,30)$. Therefore, single use of purple light-activated photoinitiators such as Lucirin TPO is not recommended for bulk fill composites (31). In contrast to camphorquinone, having an absorption peak close to 470 $\mathrm{nm}$, the absorption peak of Lucirin TPO is close to $390 \mathrm{~nm}$. As a result, ultraviolet light with a wavelength ranging from $340 \mathrm{~nm}$ to $430 \mathrm{~nm}$ is required to activate photoinitiator (32). The first and second generations of the light-emitting diode (LED) light curing units used in dentistry emit blue light at a narrow wavelength between 410 and $470 \mathrm{~nm}$. It has been noted that $\mathrm{CQ}$ cannot suitably polymerize resin materials partly replacing alternative photoinitiators (33-35). The results of our study support these findings as well. The $2 \mathrm{~mm}$ thickness of polymerization depth of photoinitiator TPO and Ivocerin containing Tetric N-Ceram bulk fill groups along with camphorquinone were found significantly lower than other composites. Tetric groups with $4 \mathrm{~mm}$ thickness presented low polymerization depth results compared to other groups. However, the difference was not found statistically significant. Some studies have highlighted that Tetric N-Ceram and Tetro Evo-Ceram containing Ivocerin, and TPO have lower surface hardness $(21,36)$.

All groups have either reached or exceeded $80 \%$ lower/upper surface hardness threshold which is the clinically acceptable ratio at the end of polymerization at 20 seconds standard and at 25 seconds soft-start mode. This result was also in consistency with similar studies in the literature $(37,38)$.

The DOC average in $2 \mathrm{~mm}$ thickness of Admira X-tra and Ecosite bulk fill composites in the Mode 1 procedure were found to be significantly higher than in $4 \mathrm{~mm}$ thickness (p: 0,024, p:0,014). DOC average in $2 \mathrm{~mm}$ thickness of Filtek and Grandioso bulk fill composites in Mode 2 procedure was statistically and significantly higher than in $4 \mathrm{~mm}$ thickness ( $p: 0,045, \mathrm{p}: 0,036$ ). There was no significant difference regarding DOC in $2 \mathrm{~mm}$ and $4 \mathrm{~mm}$ thickness in other composites. Marais et al. have also reported that the polymerization effect was gradually decreased at the thicknesses exceeding $2 \mathrm{~mm}$ in light intensity (39). Similarly, conventional and bulk fill composites have been reported to reduce light transmittance at increased thicknesses (37). The first null hypothesis of our study has been partially rejected.

When all groups were considered, there was no significant difference observed between the polymerization procedures. There are studies in the literature reporting that the continuous and gradual light-application procedures do not make a significant difference $(39,40)$. The results of our study were also in consistency with the studies in the literature. It could be stated that the performance of the soft-start technique is the same with the performance of the standard light application procedure for polymerization success. The second null hypothesis of our study has been partially rejected.

The soft start technique is an improved method used for reducing polymerization shrinkage. It will also be appropriate to evaluate the polymerization shrinkage of the materials examined in our study for polymerization success.

According to the results of our study, it could be highlighted that the application of bulk-fill resin composite in $4 \mathrm{~mm}$ layers can save us time. Moreover, the polymerization with soft start technique is not different from the standard-mode for polymerization depth. The selection of an appropriate light curing device plays an important role for reliable and durable restoration as well as the selection of bulk-fill resin composite.

\section{CONCLUSION}

Based on the current results and within the limitations of the present study, it can be concluded :

-the application of bulk-fill resin composite in $4 \mathrm{~mm}$ have reached and exceeded $80 \%$ lower/upper surface hardness ratio threshold being the clinically acceptable ratio and

-the polymerization with soft start technique may not different from the standard-mode for polymerization depth.

Acknowledgement:The experiments of the study were performed in Trakya University Technology Research Development Application and Research Center.

\section{REFERENCES}

[1] Lindberg A, Peutzfeldt A, van Dijken JW. Effect of power density of curing unit, exposure duration, and light guide distance on composite depth of cure. Clin Oral Investig 2005; 9:71-76.

[2] Pianelli C, Devaux J, Bebelman S, Leloup G. The microRaman spectroscopy, a useful tool to determine the degree of conversion of light-activated composite resins. J Biomed Mater Res 1999; 48:675-681.

[3] Caughman WF, Caughman GB, Shiflett RA, Rueggeberg F, Schuster GS. Correlation of cytotoxicity, filler loading and curing time of dental composites. Biomaterials 1991; 12:737740.

[4] Ferracane JL, Mitchem JC, Condon JR, Todd R. Wear and marginal breakdown of composites with various degrees of cure. J Dent Res 1997; 76:1508-1516. 
[5] Kovarik R, Ergle J. Fracture toughness of posterior composite resins fabricated by incremental layering. J Prosthet Dent 1993; 69:557-560.

[6] Knežević A, Tarle Z, Meniga A, Sutalo J, Pichler G, Ristić $M$. Degree of conversion and temperature rise during polymerization of composite resin samples with blue diodes. $\rfloor$ Oral Rehabil 2001; 28:586-591.

[7] Son SA, Park JK, Seo DG, Ko CC, Kwon YH. How light attenuation and filler content affect the microhardness and polymerization shrinkage and translucency of bulk-fill composites? Clin Oral Investig 2017; 21:559-565.

[8] Kramer N, Lohbauer U, García-Godoy F, Frankenberger R. Light curing of resin-based composites in the LED era. Am J Dent 2008; 21:135.

[9] Martin F. A survey of the efficiency of visible light curing units. J Dent 1998; 26:239-243.

[10] Abbas G, Fleming GJP, Harrington E, Shortall AC, Burke FJ. Cuspal movement and microleakage in premolar teeth restored with a packable composite cured in bulk or in increments. J Dent 2003; 31:437-444.

[11] Howard B, Wilson ND, Newman SM, Pfeifer CS, Stansbury JW. Relationships between conversion, temperature and optica properties during composite photopolymerization. Acta Biomater 2010; 6:2053-2059.

[12] Bucuta S, llie N. Light transmittance and micro-mechanica properties of bulk fill vs. conventional resin based composites. Clin Oral Investig 2014; 18:1991-2000.

[13] Czasch P,llie N. In vitro comparison of mechanical properties and degree of cure of bulk fill composites. Clin Oral Investig 2013; 17:227-235.

[14] Garoushi S, Vallittu P, Shinya A, Lassila L. Influence of increment thickness on light transmission, degree of conversion and micro hardness of bulk fill composites. Odontology 2016; 104:291-297.

[15] Schattenberg A, Lichtenberg D, Stender E, Willershausen $B$, Ernst CP. Minimal exposure time of different LED-curing devices. Dent Mater 2008; 24:1043-1049.

[16] Tsai P. Depth of cure and surface microhardness of composite resin cured with blue LED curing lights. Dent Mater 2004; 20:364-369.

[17] Campodonico CE, Tantbirojn D, Olin PS, Versluis A. Cuspa deflection and depth of cure in resin-based composite restorations filled by using bulk, incremental and transtoothillumination techniques. J Am Dent Assoc 2011; 142:11761182.

[18] Bouschlicher M, Rueggeberg F,Wilson B. Correlation of bottom-to-top surface microhardness and conversion ratios for a variety of resin composite compositions. Oper Dent 2004; 29:698-704.

[19] Garcia D, Yaman P, Dennison J, Neiva G. Polymerization shrinkage and depth of cure of bulk fill flowable composite resins. Oper Dent 2014; 39:441-448.

[20] Herrero AA, Yaman P,Dennison JB. Polymerization shrinkage and depth of cure of packable composites. Quintessence Int 2005; 36:449.

[21] Flury S, Hayoz S, Peutzfeldt A, Hüsler J, Lussi A. Depth of cure of resin composites: is the ISO 4049 method suitable for bulk fill materials? Dent Mater 2012; 28:521-528.

[22] Rueggeberg FA, Ergle JW,Mettenburg DJ. Polymerization depths of contemporary light-curing units using microhardness. Esthet Dent 2000; 12:340-349.
[23] Alrahlah A, Silikas N,Watts DC. Post-cure depth of cure of bulk fill dental resin-composites. Dent Mater 2014; 30:149-154.

[24] Arikawa H, Kanie T, Fujii K, Takahashi H, Ban S. Effect of inhomogeneity of light from light curing units on the surface hardness of composite resin. Dent Mater J 2008; 27:21-28.

[25] Tarle Z, Attin T, Marovic D, Andermatt L, Ristic M, Tauböck TT. Influence of irradiation time on subsurface degree of conversion and microhardness of high-viscosity bulk-fill resin composites. Clin Oral Investig 2015; 19:831-840.

[26] Skrtic D,Antonucci JM. Effect of chemical structure and composition of the resin phase on vinyl conversion of amorphous calcium phosphate-filled composites. Polym Int 2007; 56:497-505.

[27] Stansbury JW. Dimethacrylate network formation and polymer property evolution as determined by the selection of monomers and curing conditions. Dent Mater 2012; 28:13-22.

[28] Cardoso Kaord, Zarpellon DC, Madruga CFL, Rodriguez JA, Arrais CAG. Effects of radiant exposure values using second and third generation light curing units on the degree of conversion of a lucirin-based resin composite. J Appl Oral Sci 2017; 25:140-146.

[29] Shimokawa C, Sullivan B, Turbino M, Soares CJ, Price RB. Influence of emission spectrum and irradiance on light curing of resin-based composites. Oper Dent 2017; 42:537-547.

[30] Harlow J, Rueggeberg F, Labrie D, Sullivan B, Price RB. Transmission of violet and blue light through conventional (layered) and bulk cured resin-based composites. J Dent 2016; 53:44-50.

[31] Shimokawa CAK, Turbino ML, Giannini M, Braga RR, Price RB. Effect of light curing units on the polymerization of bulk fill resin-based composites. Dent Mater 2018; 34:1211-1221.

[32] Neumann MG, Miranda Jr WG, Schmitt CC, Rueggeberg FA, Correa IC. Molar extinction coefficients and the photon absorption efficiency of dental photoinitiators and light curing units. J Dent 2005; 33:525-532.

[33] Ilie N, Hickel R. Can CQ be completely replaced by alternative initiators in dental adhesives? Dent Mater J 2008; 27:221-228.

[34] Rueggeberg FA, Swift Jr EJ. Exposure times for contemporary composites. J Esthet Restor Dent 2013; 25:82-84.

[35] UhI A, Sigusch BW, Jandt KD. Second generation LEDs for the polymerization of oral biomaterials. Dent Mater 2004; 20:8087.

[36] Jang JH, Park SH, Hwang IN. Polymerization shrinkage and depth of cure of bulk-fill resin composites and highly filled flowable resin. Oper Dent 2015; 40:172-180.

[37] Karacolak G, Turkun LS, Boyacioglu H, Ferracane JL. Influence of increment thickness on radiant energy and microhardness of bulk-fill resin composites. Dent Mater J 2018; 37:206-213.

[38] Kim EH, Jung KH, Son SA, Hur B, Kwon YH, Park JK. Effect of resin thickness on the microhardness and optical properties of bulk-fill resin composites. Restor Dent Endod 2015; 40:128135.

[39] Marais J, Dannheimer M, Germishuys P, Germishuys PJ, Borman JW. Depth of cure of light-cured composite resin with light-curing units of different intensity. J Dent Assoc S Afr 1997; 52:403-407.

[40] Feilzer A, Dooren L, De Gee A, Davidson CL. Influence of light intensity on polymerization shrinkage and integrity of restoration-cavity interface. Eur J Oral Sci 1995; 103:322-326. 
How to cite this article: Ozyurt E, Kurt A, Yildirim H. Evaluation of the Polymerization Depth of Bulk Fill Resin Composites Polymerized by Different Procedures: An In-Vitro Study. Clin Exp Health Sci 2019; 9: 304-309. DOI: 10.33808/clinexphealthsci.529030 